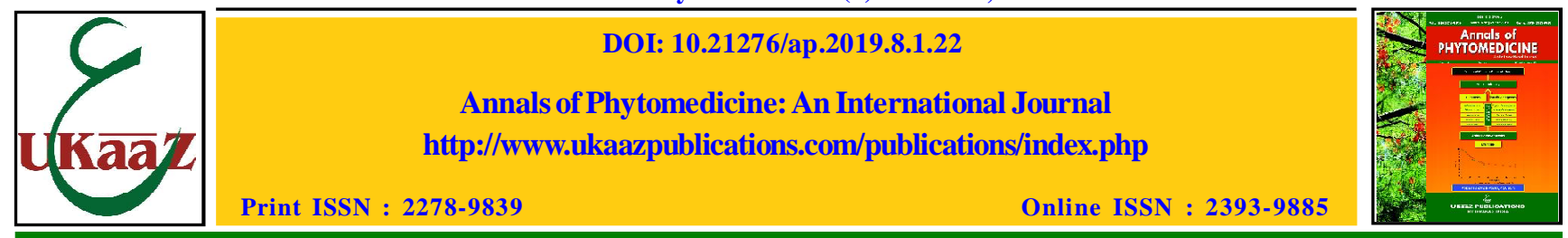

Original article

\title{
Quantification of lupeol in selected popular cultivars of mango (Mangifera indica L.) cultivated in Telangana state of India
}

\author{
B. Soujanya and A. Kiran Kumar* \\ Sri Konda Laxman Telangana State Horticultural University, Rajendranagar-500030, Telangana State, India \\ *Senior Scientist, Horticulture, Fruit Research Station, Sangareddy-502 001, Telangana State, India
}

Received March 10, 2019: Revised April 25, 2019: Accepted April 27, 2019: Published online June 30,2019

\begin{abstract}
Mango (Mangifera indica L.) is a fruit consumed worldwide, being one of the most commonly consumed fruits in the tropical countries, hence, called the 'king of fruits'. Lupeol (Lupa-21, 20 (29) dien 3 beta-ol) is a naturally occurring pentacyclictriterpene (also known as Fagarsterol) under the lupanetriterpene family, predominantly present in mango. High concentrations of lupeol are found in the peels of mango fruits, especially during the maturity stage $(180 \mu \mathrm{g} / 100 \mathrm{~g}$ average); it is very potential triterpene which acts against many diseases, especially cancer which indicates a large scope in the pharmaceutical industries. To investigate the "quantification of lupeol in selected popular cultivars of mango (M. indica), cultivated in Telanagana State of India", through high performance liquid chromatography (HPLC) method, using completely randomized design with 2 factors. One of the factors is 12 cultivars and another factor is 3 storage days. This is the first report of lupeol in mango cultivars, grown in Telangana state. Significant differences were noted among the cultivars and storage days. The maximum amount of lupeol $(67.22 \pm 11.09 \mu \mathrm{g} / 100 \mathrm{~g})$ was recorded in cultivar, Chinnarasam, whereas minimum lupeol was perceived in Himayath $(8.3 \pm 0.9 \mu \mathrm{g} / 100 \mathrm{~g})$. Among the storage days, highest lupeol content was recorded on $8^{\text {th }}(39.11 \pm 7.63 \mu \mathrm{g} / 100 \mathrm{~g})$ day of storage. The results consolidated that Chinnarasam is a juicy cultivar, grown in Telangana state and it had highest lupeol content in pulp rather than the rest of cultivars of mango.
\end{abstract}

Keywords: Lupeol, triterpine, pharmaceutical, mango cultivars, storage days

\section{Introduction}

The mango (Mangifera indica L.) is a juicy stone fruit (drupe) and also one of the most important climacteric tropical fruits in the world and currently ranked $5^{\text {th }}$ in total world production among the major fruit crops (Ravani and Joshi, 2013). It belongs to the family Anacardiaceae $(2 \mathrm{n}=40)$ and originated in Southeast Asia. It is the national fruit of India and Philippines and the national tree of Bangladesh. Enormous genetic diversity in mango exists in India, which is the primary centre of domestication of this crop. There are 1000 mono embryonic and polyembryonic mango cultivars in India (Negi, 2000).

India, China, Indonesia and Mexico are the world leaders in mango production. The principal mango producing states are Uttar Pradesh, Karnataka, Andhra Pradesh, Telangana, Bihar, West Bengal and Gujarat. India is the largest producer and prominent exporter of mango with annual production of 19.68 million tonnes and share of more than one-third (which accounts $36 \%$ ) of the world's mango production (FAOSTAT, 2017). In India, mango is cultivated in an area of 2263 thousand hectares with production of 196.87 lakh tonnes and 8.7 MT/ha productivity. Major mango growing states are Uttar Pradesh, Karnataka, Andhra Pradesh, Telangana, Bihar,

\footnotetext{
Author for correspondence: Ms. B. Soujanya

Sri Konda Laxman Telangana State Horticultural University, Rajendranagar-500030, Telangana State, India

E-mail: bsoujanya129@gmail.com

Tel.: +91-9989431077
}

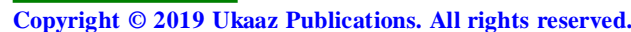

Email: ukaaz@yahoo.com; Website: www.ukaazpublications.com
West Bengal and Gujarat. Telangana state occupies $4^{\text {th }}$ position in India. In Telangana area, production and productivity of mango to be 180.62 thousand ha, $1681.6 \mathrm{MT}$ and $9.3 \mathrm{MT} / \mathrm{ha}$, respectively. (NHB Database, 2017).

Mangoes can be considered as a good source of dietary antioxidants, such as ascorbic acid, carotenoids and phenolic compounds. Having been part of the indigenous medical systems for over 4000 years, mango fruits have been considered a good source of bioactive compounds that can be used towards preventing diseases and promoting overall good health in humans (Chaturvedi et al., 2008). Mango is naturally rich in fiber $(1.6 \mathrm{~g} / 100 \mathrm{~g})$, antioxidant, vitamin A $(54 \mu \mathrm{g} / 100 \mathrm{~g})$ and vitamin C (36.4 mg/100 g) and vitamin B6 (0.119 $\mathrm{mg} / 100 \mathrm{~g}$ ) (Lemmens and Emmanuel, 2013; Rincon and Keer, 2010; Sogi and Ibrahim, 2012) present in mango peel and pulp, such as triterpene, lupeol which is under basic research for its potential biological effects. The fruit also contains substances called triterpene and lupeol, which inhibit skin and colon cancer.

There is a growing interest in natural triterpenoids, also known as phytosterols, due to their wide spectrum of biological activities (Ovesná et al., 2004). Lupeol is a pharmacologically active triterpenoid. It has several potential medicinal properties. Triterpenoids lupeol are compound with a carbon skeleton based on six isoprene units which are derived biosynthetically from the acyclic C30 hydrocarbon squalene. It is found in all vegetables, fruits and medicinal plants. Lupeol has a complex pharmacology, display antiprotozoal, antimicrobial, anti-inflammatory, antitumor and chemopreventive properties (Rahman and Saleem, 2011). 
Lupeol is a novel anti-inflammatory and anticancer dietary triterpine (Mahammod, 2009).

The objectives of present research work is to estimate/quantify the lupeol content in selected popular cultivars (12 Table and Juicy cultivars) of mango taking into consideration of 3 storage days ( $4^{\text {th }}$, $8^{\text {th }}$ and $12^{\text {th }}$ day) at ambient conditions. High performance liquid chromatography method is suitable method for estimation of lupeol content present in mango pulp, by using methanol:acetonitrile (30:70\%) solvent as mobile phase and C18 column as stationary phase and DAD (diode array detector) at $210 \mathrm{~nm}$, flow rate of $1 \mathrm{ml} / 1 \mathrm{~min}$ carried out at MFPI-Quality Control Laboratory, PJTSAU, Rajendranagar, Hyderabad, India.

\section{Materials and Methods}

12 (Table and Juicy) cultivars of mango (M. indica) fruits were collected from the Fruit Research Station, Sangareddy, India in the year of 2016. Cultivars were harvested at fully matured stage (Juicy varieties harvested at $7-9^{\circ} \mathrm{B}$ and Table varieties harvested at $8-9^{\circ} \mathrm{B}$ ) subjected to ethylene treatment kept for storage at ambient conditions up to 12 days.

\subsection{Chemicals and reagents}

Pharmaceutical grade lupeol was purchased from Sigma Aldrich (Mumbai, India) and all other solvents (methanol and acetonitrile) were used for estimation of lupeol are HPLC grade and purchased from Merck Ltd., Mumbai, India). Solvents were filtered through a $0.45 \mu \mathrm{m}$ membrane filter, $\mathrm{C} 18(250 \times 4.6 \mathrm{~mm})$ column was used for analysis.

\subsection{Standard preparation}

A stock solution of lupeol was prepared by dissolving $1 \mathrm{mg} / \mathrm{ml}$ of accurately weighed lupeol in methanol : acetonitrile $(3: 7 \mathrm{~V} / \mathrm{V})$, making up the volume to $10 \mathrm{ml}$. Six working solutions of respective compounds were prepared by dilution. $0.5 \mathrm{ppm}, 1 \mathrm{ppm}, 5 \mathrm{ppm}, 10$ ppm, $15 \mathrm{ppm}$ and $20 \mathrm{ppm}$ were prepared by the stock solution.

\subsection{Sample preparation}

Twelve cultivars of mango fruits were subjected to pulp extraction and extracted pulp was kept for drying in solar drier for 15 days at $60^{\circ} \mathrm{C}$. The extraction efficiency of target compound was optimized by using solvent mixture of methanol and acetonitrile $(3: 7 \mathrm{~V} / \mathrm{V})$ was selected to extract the lupeol content in pulp of mango $(250 \mathrm{mg})$ powder. Mango pulp powder $(250 \mathrm{mg})$ was extracted through 10 $\mathrm{ml}$ of methanol:acetonitrile $(3: 7 \mathrm{~V} / \mathrm{V})$ and filtered through Watman No. 1 filter paper and vortex $5 \mathrm{~min}$, after this kept for overnight at room temperature. Next day, solution was again subjected to vortex for $5 \mathrm{~min}$ and finally filtered through $0.45 \mu \mathrm{m}$ membrane filter and used for further chromatographic analysis.

\subsection{Chromatographic conditions}

Quantification of lupeol was done by HPLC (High Performance Liquid Chromatography). Mobile phase was prepared by methanol and acetonitrile (30:70 V/V) solvents. Solvents degassed and filtered through $0.2 \mu \mathrm{m}$ filters. C18 column $(254 \times 4.6 \mathrm{~mm})$, column flow rate was $1 \mathrm{ml} / \mathrm{min}$, column temperature was $25^{\circ} \mathrm{C}$ and wave length was $210 \mathrm{~nm}$ and injection volume was $20 \mu \mathrm{l}(0.02 \mathrm{ml})$. DAD (diode array detector) was used for the detection of targeted compound at
$210 \mathrm{~nm}$. It was made with deuterium lamp. Lupeol standard showed its peak at 27.5 to $28.5 \mathrm{~min}$ of HPLC isocratic method.

\subsection{Detection of lupeol}

The identity of band of lupeol in dried mango powder samples $(250 \mathrm{mg}$ ) was confirmed by DAD detector with standard lupeol at periodical intervals of $4^{\text {th }}, 8^{\text {th }}$ and $12^{\text {th }}$ day of storage. Finally, lupeol $(\mu \mathrm{g} / 100 \mathrm{~g})$ amount was calculated on the basis of following formula given by Anyakora et al. (2008).

$\frac{\text { Sample peak area }}{\text { Std peak area }} \times$ Conc. Of Std X $\frac{\text { Vol. of dilution X } 100}{\text { Injection Volume X wt of Sample }}$

Dil $=$ dilution, $\mathrm{Wt}=$ weight, Conc $=$ Concentration, $\mathrm{Std}=$ standard .

\subsection{Statistical analysis}

The design adopted was completely randomized design with 2 factors (storage days and varieties). Statistical analysis was performed in 2 replicates of samples and the results were presented as Mean \pm standard deviation. Data were processed at the Computer Centre, Hyderabad, using (SAS version 9.1, Statistical Analysis System Institute, Inc. C).

\section{Results}

Lupeol is a non-polar compound, estimated by RP-HPLC (reverse phase high performance liquid chromatography) and detected by DAD (diode array detector).

On the basis of results obtained as the storage days increased, there was significant increase in lupeol content from $4^{\text {th }}$ day to $8^{\text {th }}$ day and later decreased on $12^{\text {th }}$ day of storage. Among the 12 cultivars, Table and Juicy cultivars significantly $(p<0.05)$, high amount of lupeol was recorded in the cultivar Chinnarasm $(67.22 \pm 11.09 \mu \mathrm{g} /$ $100 \mathrm{~g})$, followed by Baneshan $(50.88 \pm 12.25 \mu \mathrm{g} / 100 \mathrm{~g})$, Allampur Baneshan $(49.88 \pm 28.56 \mu \mathrm{g} / 100 \mathrm{~g})$ and Suvarnarekha $(47.22 \pm$ $17.92 \mu \mathrm{g} / 100 \mathrm{~g})$. While, lowest amount was noticed in cultivar Himayath $(8.27 \pm 0.94 \mu \mathrm{g} / 100 \mathrm{~g})$ and, followed by Pandurivari Mamidi $(8.40 \pm 0.11 \mu \mathrm{g} / 100 \mathrm{~g})$. Quantity of lupeol varied from $8.27 \pm 0.94 \mu \mathrm{g} / 100 \mathrm{~g}$ to $67.22 \pm 11.09 \mu \mathrm{g} / 100 \mathrm{~g}$ among the 12 cultivars whereas Table and Juicy cultivars showed highest lupeol content whereas recorded in Juicy variety, Chinnarasam and lowest noticed in Himayath, indicating that lupeol content was highest in almost all cultivars Table and Juicy cultivars at fully ripened stage.

Significant differences were noted in relation to storage days $\left(4^{\text {th }}\right.$, $8^{\text {th }}$ and $12^{\text {th }}$ day of storage), the highest amount of lupeol was noticed on $8^{\text {th }}$ day of storage $(39.11 \pm 7.63 \mu \mathrm{g} / 100 \mathrm{~g})$, followed by $12^{\text {th }}$ day of storage $(38.95 \pm 7.22 \mu \mathrm{g} / 100 \mathrm{~g})$ and lowest was noticed on $4^{\text {th }}$ day of storage $(27.11 \pm 6.92 \mu \mathrm{g} / 100 \mathrm{~g})$. It is indicating that lupeol content maximum at ripened stage rather than the fully ripened stage when stored at ambient conditions.

The interaction between 12 cultivars (Table and Juicy cultivars) and 3 storage days $\left(4^{\text {th }}, 8^{\text {th }}\right.$ and $12^{\text {th }}$ day of storage) showed significant variation (Table I). Significantly highest amount of lupeol was recorded in Allampur Baneshan $(140.19 \pm 0.04 \mu \mathrm{g} / 100 \mathrm{~g})$ on $8^{\text {th }}$ day, followed by Mahamooda Vikarabad $(117.34 \pm 0.01 \mu \mathrm{g} / 100 \mathrm{~g})$ on $12^{\text {th }}$ day of storage and Chinnarasam $(102.31 \pm 0.02 \mu \mathrm{g} / 100 \mathrm{~g})$ on $4^{\text {th }}$ day of storage, while significantly lowest amount of lupeol 
was recorded in Mahamooda Vikarabad $(1.27 \pm 0.02 \mu \mathrm{g} / 100 \mathrm{~g})$ on $8^{\text {th }}$ day of storage, followed by Suvarnarekha $(1.81 \pm 0.03 \mu \mathrm{g} / 100 \mathrm{~g})$ and Manjeera $(2.66 \pm 0.00 \mu \mathrm{g} / 100 \mathrm{~g})$ on $4^{\text {th }}$ day of storage.

Luepol content in Table and Juicy cultivars of mango represented in Table 1 and Figure 1. Some of the chromatograms are presented in Figure 2 to Figure 5 which are related to the lupeol content in samples of 12 mango cultivars on 3 different storage days at ambient conditions.

Table 1: Lupeol content in dried mango powder $(\mu \mathrm{g} / 100 \mathrm{~g})$ as influenced by storage days $\left(4^{\text {th }}, 8^{\text {th }}\right.$ and $12^{\text {th }}$ day) at ambient conditions in 12 mango cultivars

\begin{tabular}{|c|c|c|c|c|}
\hline \multirow[b]{2}{*}{ Varieties } & \multicolumn{4}{|c|}{ Storage days } \\
\hline & $4^{\text {th }}$ day & $8^{\text {th }}$ day & $12^{\text {th }}$ day & Mean \\
\hline Baneshan & $70.18 \pm 0.00$ & $70.32 \pm 0.03$ & $12.13 \pm 0.01$ & $50.88 \pm 12.25^{\mathrm{h}}$ \\
\hline Himayath & $9.85 \pm 0.02$ & $9.67 \pm 0.02$ & $5.32 \pm 0.01$ & $8.27 \pm 0.94^{\mathrm{a}}$ \\
\hline Totapari & $75.84 \pm 0.03$ & $3.31 \pm 0.01$ & $50.55 \pm 0.07$ & $43.23 \pm 13.44^{\mathrm{e}}$ \\
\hline Suvarnarekha & $1.81 \pm 0.03$ & $40.59 \pm 0.01$ & $99.27 \pm 0.04$ & $47.22 \pm 17.92^{\mathrm{f}}$ \\
\hline MahamoodaVikarabad & $11.55 \pm 0.04$ & $1.27 \pm 0.02$ & $117.34 \pm 0.01$ & $43.39 \pm 23.46^{\mathrm{e}}$ \\
\hline Vanraj & $19.07 \pm 0.04$ & $33.71 \pm 0.04$ & $33.83 \pm 0.02$ & $28.87 \pm 3.10^{\mathrm{d}}$ \\
\hline AllampurBaneshan & $5.34 \pm 0.01$ & $140.19 \pm 0.04$ & $4.13 \pm 0.01$ & $49.89 \pm 28.56^{\mathrm{g}}$ \\
\hline Manjeera & $2.66 \pm 0.00$ & $49.67 \pm 0.01$ & $24.70 \pm 0.03$ & $25.68 \pm 8.59^{c}$ \\
\hline Mulgoa & $13.20 \pm 0.00$ & $31.53 \pm 0.01$ & $31.55 \pm 0.01$ & $25.43 \pm 3.87^{b}$ \\
\hline Navaneetham & $5.37 \pm 0.01$ & $30.75 \pm 0.00$ & $30.47 \pm 0.06$ & $22.20 \pm 5.32^{\mathrm{b}}$ \\
\hline Chinnarasam & $102.31 \pm 0.01$ & $49.71 \pm 0.01$ & $49.65 \pm 0.01$ & $67.22 \pm 11.09^{\mathrm{i}}$ \\
\hline PandurivariMamidi & $8.20 \pm 0.02$ & $8.60 \pm 0.06$ & $8.40 \pm 0.02$ & $8.40 \pm 0.11^{\mathrm{a}}$ \\
\hline Mean & $27.11 \pm 6.92^{\mathrm{A}}$ & $39.11 \pm 7.63^{\mathrm{C}}$ & $38.95 \pm 7.22^{\mathrm{B}}$ & \\
\hline Factors & \multicolumn{2}{|c|}{ SEM } & \multicolumn{2}{|c|}{$\mathrm{CD}$ at $5 \%$} \\
\hline Varieties (A) & \multicolumn{2}{|c|}{0.075} & \multicolumn{2}{|c|}{0.215} \\
\hline Storage period (B) & \multicolumn{2}{|c|}{0.038} & \multicolumn{2}{|c|}{0.108} \\
\hline $\mathrm{A} \times \mathrm{B}$ & \multicolumn{2}{|c|}{0.130} & \multicolumn{2}{|c|}{0.373} \\
\hline
\end{tabular}

Note: All the values are expressed as Mean \pm SD. Values with similar superscripts are statistically similar at $5 \%$ level.

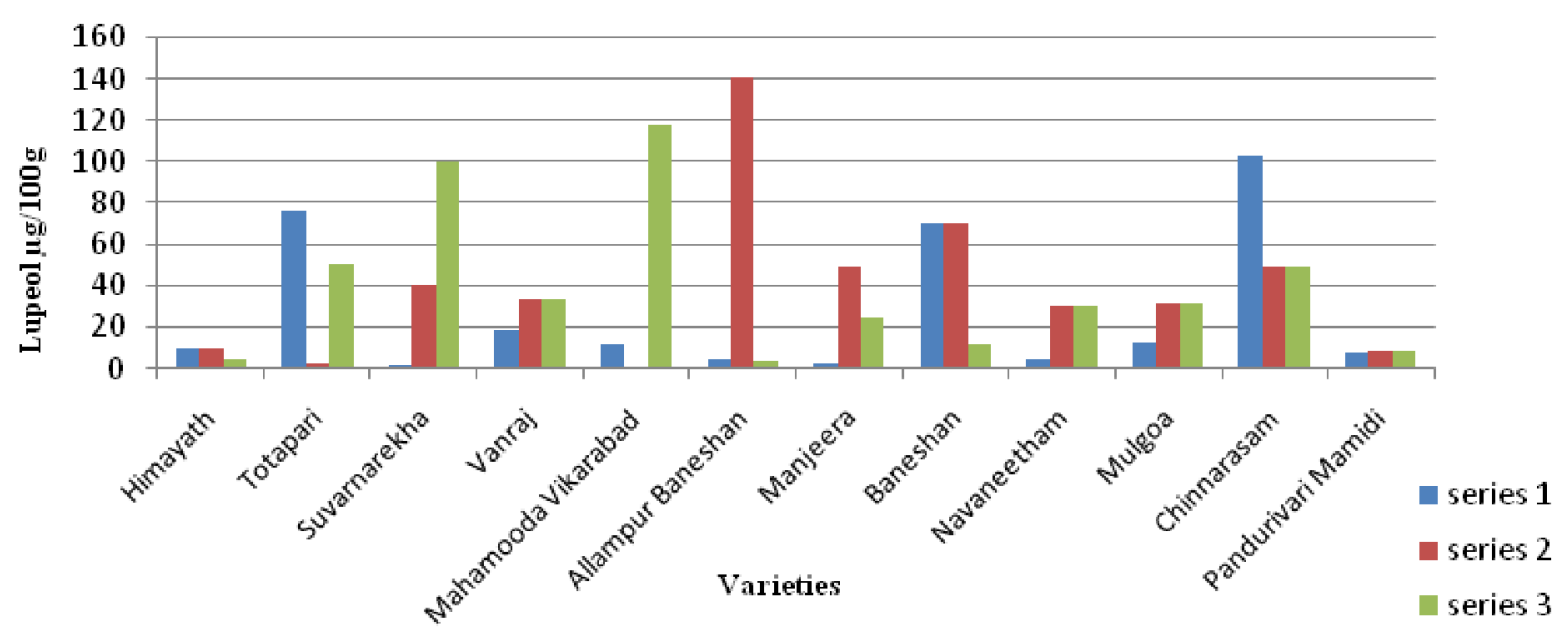

Figure 1: Lupeol content in dried mango powder $(\mu \mathrm{g} / 100 \mathrm{~g})$ as influenced by storage days $\left(4^{\text {th }}, 8^{\text {th }}\right.$ and $12^{\text {th }}$ day $)$ at ambient conditions in 12 mango cultivars. 


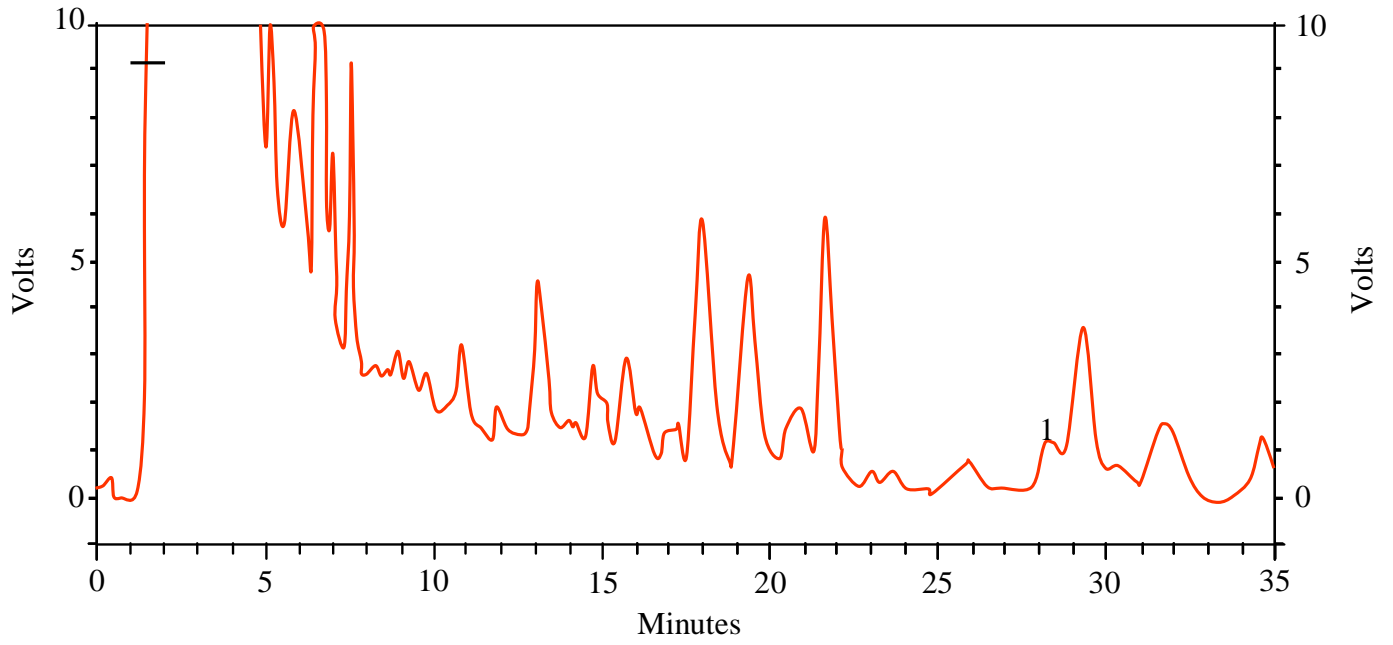

Figure 2: Chromatogram of lupeol in variety of mango Baneshan on $4^{\text {th }}$ day obtained by HPLC Agilent 1260.

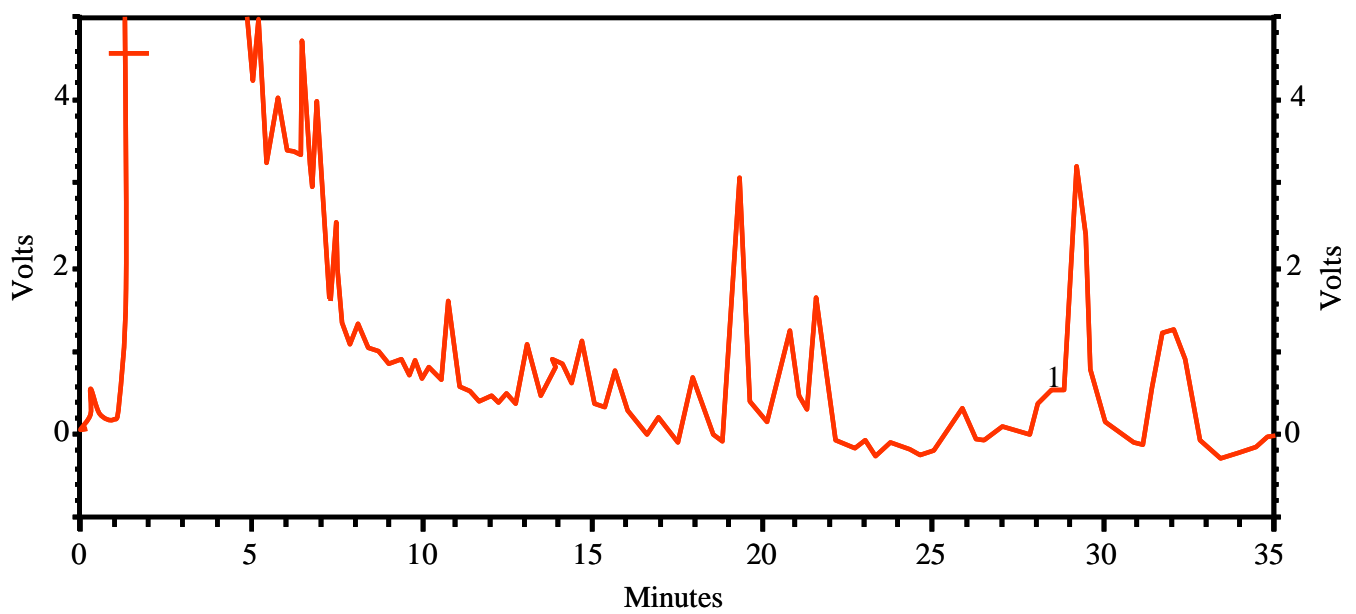

Figure 3: Chromatogram of lupeol in variety of mango Chinnarasam on $8^{\text {th }}$ day obtained by HPLC Agilent 1260.

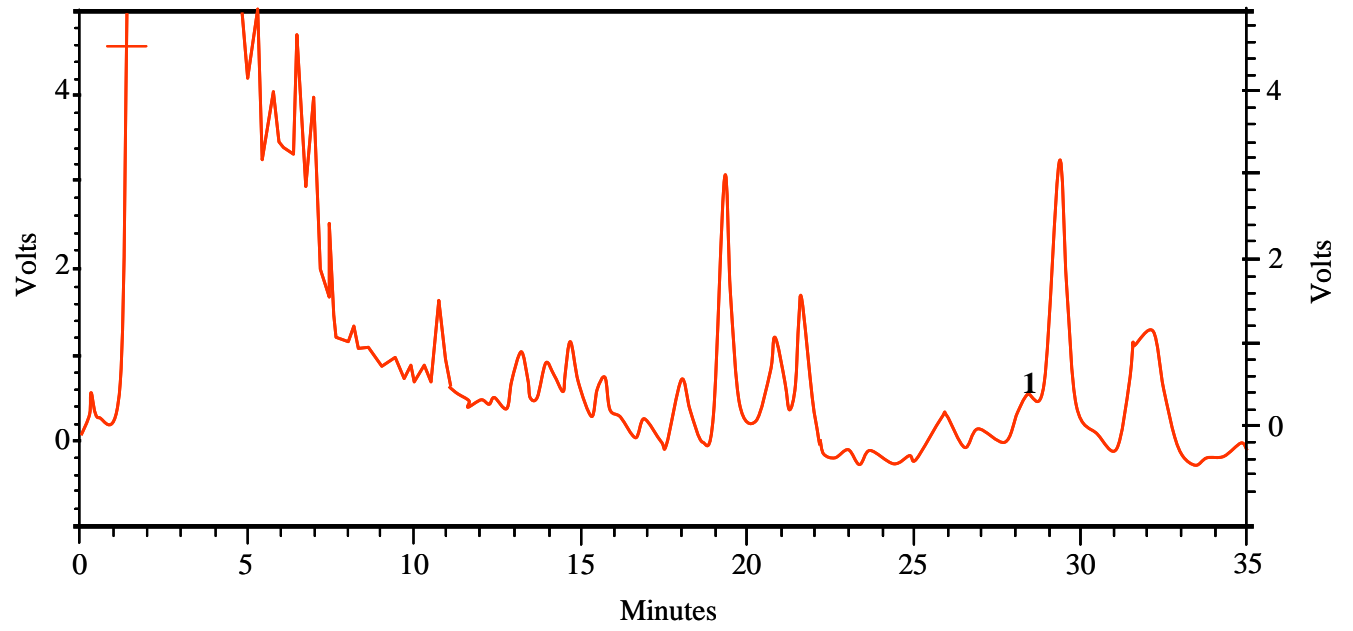

Figure 4: Chromatogram of lupeol in variety of mango Baneshan on $12^{\text {th }}$ day obtained by HPLC Agilent 1260 . 


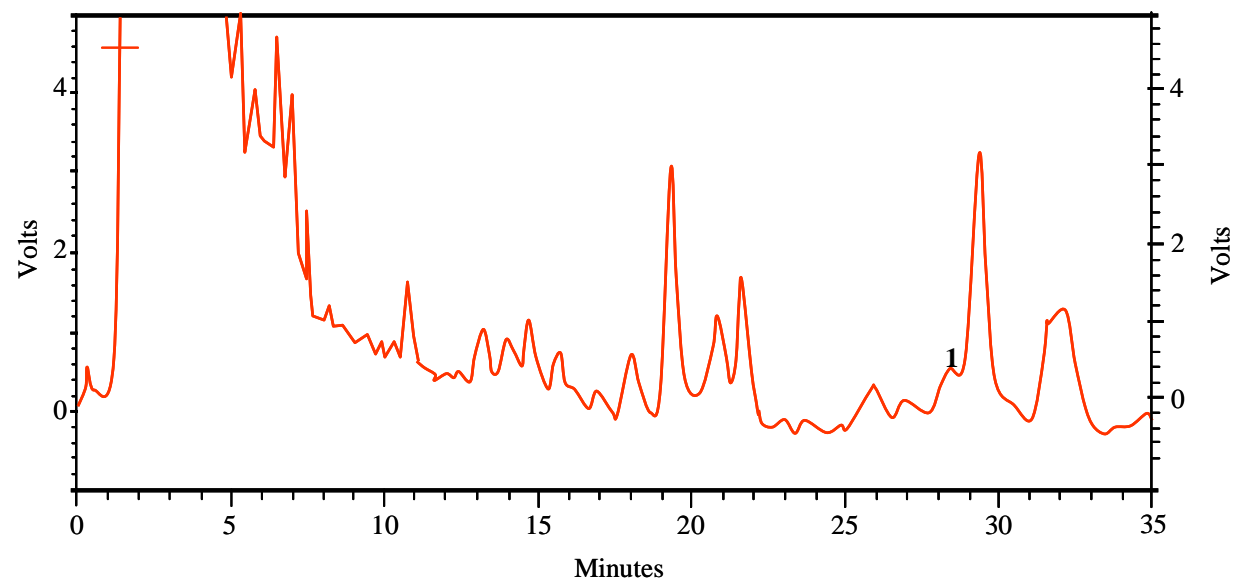

Figure 5: Chromatogram of lupeol in variety of mango Chinnarasam on $12^{\text {th }}$ day obtained by HPLC Agilent 1260.

\section{Discussion}

Above results are also in line with Soujanya et al. (2017a) who have reported that significantly highest lupeol content in colored cultivar of Suvarnarekha $(47.26 \pm 12.09 \mu \mathrm{g} / 100 \mathrm{~g})$ than Vanraj $(28.86 \pm 2.09$ $\mu \mathrm{g} / 100 \mathrm{~g})$. Among the storage days, significantly highest lupeol content recorded on $12^{\text {th }}$ day of storage $(66.60 \pm 12.33 \mu \mathrm{g} / 100 \mathrm{~g})$ while lowest was noticed on $4^{\text {th }}$ day of storage $(10.44 \pm 3.26 \mu \mathrm{g} /$ $100 \mathrm{~g}$ ) and also same line of research reported in Juicy varieties of mango by Soujanya et al. (2017b), suggested that significantly Chinnarasam recorded highest amount of lupeol (67.24 $\pm 8.77 \mu \mathrm{g} /$ $100 \mathrm{~g})$. While lowest amount of lupeol was recorded in Pandurivari Mamidi $(8.45 \pm 0.10 \mu \mathrm{g} / 100 \mathrm{~g})$. Among the storage days, significantly highest amount of lupeol was recorded in 4th day of storage $(38.63 \pm 15.93 \mu \mathrm{g} / 100 \mathrm{~g})$. While 8 th and 12 th day of storage were recorded similar amount of lupeol content $29.73 \pm 5.93 \mu \mathrm{g} /$ $100 \mathrm{~g}$ and $29.53 \pm 5.94 \mu \mathrm{g} / 100 \mathrm{~g}$, respectively.

The results are in agreement with Jyotshna et al. (2015) who have estimated luepol and mangiferin content in 4 mango cultivars and results showed that highest amount of lupeol was noticed in Dashehari $(1082 \mu \mathrm{g} / 100 \mathrm{~g})$ as compared to Bombay green $(505 \mu \mathrm{g} /$ $100 \mathrm{~g})$, Langra $(167 \mu \mathrm{g} / 100 \mathrm{~g})$ and Chausa $(65 \mu \mathrm{g} / 100 \mathrm{~g})$ in pulp and peel during storage period. Similar results were reported by Saratha et al. (2011).

Ruiz et al. (2014) noticed that bioactive compounds, mangiferin and lupeol in higher concentrations at physiological maturity stage in Atulfo mango fruit peel.

As seen from above discussed results by different researchers on lupeol, there is a huge scope on lupeol quantification from available sources of plants which can be helpful for the preparation of many pharmaceuticals and fight against different diseases, especially against cancer. Present study can be useful to quantify essential triterpenes (lupeol) from all available cultivars of mango because there is a large number of mango varieties which are available in our country.

\section{Conclusion}

Mango varieties (12 commercial/popular cultivars) were tested for their lupeol content in pulp. Good results have been noticed regarding the lupeol content in the selected mango cultivars (Table and Juicy cultivars), however, there was a lot of variation observed among the cultivars and lupeol content ranged from $8.27 \pm 0.94 \mu \mathrm{g} /$ $100 \mathrm{~g}$ (Himayath) to $67.22 \pm 11.09 \mu \mathrm{g} / 100 \mathrm{~g}$ (Chinnarasam). Highest lupeol content was recorded in Chinnarasam $(67.22 \pm 11.09 \mu \mathrm{g} / 100$ g) which is a Juicy cultivar, majorly grown in Telangana state. Among the 3 storage days, lupeol content varied from $27.11 \pm 6.92$ to $39.11 \pm 7.63 \mu \mathrm{g} / 100 \mathrm{~g}$ ( $4^{\text {th }}$ and $8^{\text {th }}$ day of storage, respectively). Among the storage days, lupeol content was highest on $8^{\text {th }}$ day of storage $(39.11 \pm 7.63 \mu \mathrm{g} / 100 \mathrm{~g})$. As evident from the study promising, lupeol content $(\mu \mathrm{g} / 100 \mathrm{~g})$ was noticed among the cultivars and there is a lot of variation in the content level of lupeol among cultivars. This study can be helpful in estimation lupeol content from all available cultivars of mango in the country.

\section{Acknowledgements}

The authors wish to thank the Fruit Research Station (FRS, Sangareddy, India) and authors also acknowledge Sri Konda Laxman Telangana State Horticultural University (SKLTSHU) for supporting this study. We are thankful to the Head of the Fruit Research Station for this keen interest in the study.

\section{Conflict of interest}

The authors declare that no conflict of interest exists in the course of conducting this research. Both the authors had final decision regarding the manuscript and the decision to submit the findings for publication.

\section{References}

Anyakora, C.; Ibukam, A.; Teddy, E. and Francis, O. (2008). HPLC analysis of nicotinamide, pyridoxine, riboflavin and thiamin in some selected food products in Nigeria. African Journal of Pharmacy and Pharmacology, 2(2):29-36.

Chaturvedi, P. K.; Bhui, K. and Shukla, Y. (2008). Lupeol: Connotations for chemoprevention. Cancer Lett., 263:1-13.

FAOSTAT (2017). Food and Agriculture Organisation of United Nation. http://www.fao.org

Jyotshna.; Srivastava, P.; Bharti, K. and Karana, S. (2015). Unidimensional double development HPTLC-densitometry method for simultaneous analysis of (Mangifera indica L.) pulp and peel during storage. Food Chemistry, 176:91-98. 
Lemmens, L. and Emmanuel, S. (2013). Beta-carotene isomerisation in mango as influenced by thermal processing and high-pressure homogenisation. Europeon Food Research and Technology, 236(1): 155-63.

Mahammod, S. (2009). Lupeol: A novel anti-inflammatory and anticancer dietary triterpene. Cancer Letters, 285:109-15.

National Horticulture Database (2017). National Horticulture Board, Ministry of Agriculture, Government of India. http:nhb.gov.in/ area-pro/database.

Negi, S. S. (2000). Mango production in India. Acta Horticulture 509. VI International Symposium on Mango. pp:69-78.

Ovesná, Z.; Vachálková, A.; Horváthová, K. and Tóthová, D. (2004). Pentacyclictriterpenoic acids: New chemoprotective compounds: Mini review. Neoplasma, 51:327-333.

Rahman, S. and Saleem, M. (2011). Beneficial health effects of lupeoltriterpene: A review of preclinical studies. Life Sciences, 88(8):285-93.

Ravani, A. and Joshi, D.C. (2013). Mango and it's by product utilization: A review. Trends in Post-Harvest Technology., 1(1):55-67.
Rincon and Keer (2010). Influence of osmotic dehydration, ripeness and frozen storage on physicochemical properties of mango. Journal of Food Processing and Preservation, 34(5):887-903.

Ruiz, M.; Sanchez, J.A.; Calderon-Santoyo, M. and La cruz, G.V. (2014). Evaluation of extraction methods for preparative scale obtention of mangiferin and lupeol from mango peels (Mangifera indica L.). Food Chemistry, 159:267-72.

Saratha, V. and Iyyam, S.P. (2011). Isolation and characterization of lupeol, a triterpenoid from Calotropis gigantean latex. Interantional Journal of Pharmaceutical Sciences Review and Research, 10(2):54-57.

Sogi, D. and Ibrahim, G. (2012). Total phenolics, antioxidant activity, and functional properties of 'Tommy Atkins' mango peel and kernel as affected by drying methods. Food Chemistry, 141:2649-55.

Soujanya, B.; Kiran Kumar,A.; Sreedhar, M.; Aparna, K. and Ravinder Reddy. K. (2017a). Quantification of lupeol in selected commercial coloured cultivars of mango (Mangifera indica L.) cultivated in Telangana Region. Int. J. Pure App. Biosci., 5(4):2141-2146.

Soujanya, B.; Kiran Kumar, A.; Sreedhar, M.; Aparna, K. and Ravinder Reddy, K. (2017b). Quantification of lupeol in selected juicy cultivars of mango (Mangifera indica L.) popularly grown in Telangana region. Journal of Plant Development Sciences, 9(9):859-863.

Citation: B. Soujanya and A. Kiran Kumar (2019). Quantification of lupeol in selected popular cultivars of mango (Mangifera indica L.) cultivated in Telangana state of India. Ann. Phytomed., 8(1):166-171. 